\title{
Epidemiology of drug interactions in cancer patients
}

\author{
Rachel P. Riechelmann* \& Monika K. Krzyzanowska ${ }^{\ddagger}$ \\ Department of Medical Oncology and Hematology, Princess Margaret Hospital, 610 University Avenue, \\ Toronto, Ontario, M5G 2M9, Canada.
}

Correspondence to R. P. R. e-mail: Rachel.Riechelmann@uhn.on.ca

We thoroughly enjoyed reading the recent article by Scripture and Figg entitled "Drug interactions in cancer therapy"1. The authors did an extensive review of the literature on mechanisms of drug interactions, focusing on potential interactions between chemotherapeutic agents and other medications as well as food and herbal drugs. This is a neglected issue in clinical practice, and a comprehensive review on this topic is welcome. One aspect of this topic that was not covered in the review is the epidemiology of such interactions. There is very little in the literature on this particular aspect of drug interactions in oncology, but we have conducted two studies of potential drug interactions in cancer patients that can begin to give an insight into the magnitude of this problem.

The first study evaluated the frequency of potential drug interactions in 100 consecutive hospitalized cancer patients who were not receiving antineoplastic therapy ${ }^{2}$. In that study, $63 \%$ of patients were exposed to at least one potential drug interaction. Our second study evaluated the epidemiology of potential drug interactions among 405 ambulatory cancer patients who received standard cancer-directed therapy ${ }^{3}$. Using the highly accurate Drug Interactions Facts ${ }^{4}$ software, we screened for and classified drug interactions by level of severity (major, moderate or minor) and scientific evidence (1-5, with 1 representing the highest level of evidence) ${ }^{5}$. Among 405 patients, 276 potential drug interactions were identified in $27 \%$ of them. Most potential interactions involved non-anticancer agents $(87 \%)$, were classified as either major or moderate $(86 \%)$ and had good evidence in the literature (level $\leq 3: 52 \%)$. Most potential interactions related to antihypertensive agents, warfarin, aspirin and anticonvulsants.

Our data suggest that potential drug interactions are common among cancer patients, and involve not only interactions between chemotherapy agents and other medications, but between the other medications themselves. We strongly support the recommendation of Scripture and Figg that increasing awareness of the potential for drug interactions can hopefully minimize the risk of such occurrences. However, little is known about real drug interactions in oncology or the best way to increase awareness of such interactions, and more research in this area is warranted.

1. Scripture, C. D. \& Figg, W. D. Drug interactions in cancer therapy. Nature Rev. Cancer 6, 546-558 (2006).

2. Riechelmann, R. P., Moreira, F., Smaletz, O. \& Saad, E. D. Potential for drug interactions in hospitalized cancer patients. Cancer Chemother. Pharmacol. 56, 286-290 (2005).

3. Riechelmann, R. P., Tannock, I. F., Wang, L. \& Krzyzanowska, M. K. Drug interactions in ambulatory cancer patients receiving cancer-therapy. American Society of Clinical Oncology [online],

http://www.asco.org/portal/site/ASCO/menuitem.34d60f5624ba07fd506fe310ee37a01d/?vgnextoi d=76f8201eb61a7010VgnVCM100000ed730ad1RCRD\&vmview=abst_detail_view\&confID=40\&i ndex=y\&abstractID=31982 (2006).

4. Barrons, R. Evaluation of personal digital assistant software for drug interactions. Am. J. Health Syst. Pharm. 61, 380-385 (2004)

5. Wolters Kluwer. Drug Interaction Facts (software). Facts and comparisons [online], http://www.factsandcomparisons.com/Products/index.aspx?cat=6\&id=117 (1994). 